\title{
The Effect of Children's Age on Married Women's Career Reinterruption*
}

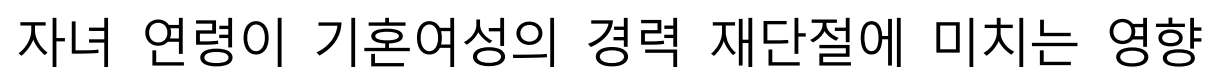

\author{
Seeun Park(박세은) $)^{* *}$, Sun $\operatorname{Go}(\text { 고선 })^{* * *}$
}

Received: June 15, 2018. Revised: June 27, 2018. Accepted: July 15, 2018.

\section{Abstract}

Purpose - The main purpose of this paper is to examine the effect of children's age on maternal labor supply in Korea using survival analysis. Specifically, we focus on the career re-interruption of women having children under age 12, which has rarely been studied in the existing literature.

Research design, data, and methodology - We use micro data from the Korea Labor and Income Panel Study (KLIPS) surveyed from 1998 to 2016. Instead of using a pre-school child dummy or the number of young children as an explanatory variable, 9 children's age dummies are included to capture the effect of nurturing 0 to 9 years old children. This study estimates the hazard of a woman's exiting the labor market after her first experience of the career interruption, rather than the hazard of the first career interruption itself. A Cox proportional hazard model is applied to numerically capture the impact of children's age on behavioral changes in maternal labor supply. The sample used in this analysis is women between 15 and 54 years old. Most of all, we restrict the sample to women who had at least a child between 0 and 12 years old at the time of quitting their jobs.

Results - The Cox proportional hazard model estimates show a strong negative effect of a 0 -year-old child on maternal labor supply. Mothers with newborns have a high hazard ratio of labor force exit after the re-entry. The hazard of women with infants is three times higher than those with children aged 10 to 18 . Additionally, the results show that not only newborns, but also children in the age of school-entry have a negative impact on their mother's labor supply.

Conclusions - The findings reveal that children's ages need to be properly expanded and included when analyzing the effect of children and their ages on married women's labor supply, especially on women's career re-interruption. A large negative effect of 7-year-old children on maternal labor supply found here indicates that supporting mothers with school age children as well as pre-school children is necessary to prevent mothers from leaving the labor market.

Keywords: Career Reinterruption, Married Women, Labor Supply, Children’s Age, Survival Analysis.

JEL Classifications: J13, J16, J22.

\section{Introduction}

「경력단절 여성 등의 경제활동 촉진법」에 따르면 경력단절 여성은 임신출산육아와 가족 돌봄 등을 이유로 경제활동을 중 단했거나 경제활동을 한 적은 없으나 취업을 희망하는 여성으

* This research was supported by the Chung-Ang University Research Scholarship Grants in 2016. This research is modified and developed from Seeun Park's Master's thesis.

** First Author, Master's student, School of Economics, Chung-Ang University, Korea. E-mail: senpark@cau.ac.kr

*** Corresponding Author, Associate Professor, School of Economics, Chung-Ang University, Korea. Tel: +82-2-820-5485,

E-mail: sungo@cau.ac.kr
로 정의된다. 여성의 경력단절은 표면적으로는 우수한 노동력 의 상실을 가져오고, 이면에서는 경력단절의 회피 노력이 저출 산 문제로 이어지는 등 다양한 측면에서 사회 전체적으로 문 제가 된다. 정부는 이러한 문제를 인식하고 기혼 여성들의 경 력단절 문제를 해결하기 위해 노동, 보육 분야에서 경력단절을 줄이기 위한 다양한 정책을 도입하였다. 그러나 지역별 고용조 사(Statistics Korea, 2017b)에 따르면, 경력단절 여성의 비율은 2011년 첫 조사 이후 감소 없이 $20 \%$ 대를 유지하고 있다.

그동안 경력단절 여성에 대한 연구는 다양하게 이루어졌다. 하지만 선행 연구에는 최초 경력 단절과 재단절이 구분되지 않았고, 자녀 효과를 단편적으로 추정했다는 한계가 있다. 그 동안 여성의 경력단절에 대한 연구는 최초 경력 단절을 주로 살펴보았고, 이를 줄이기 위한 정책들이 개발되어 실시되었다. 
하지만 최초 경력단절 후 복귀가 이루어지더라도 이후의 경제 활동 참여가 지속되지 않고 다시 단절이 발생한다면, 이러한 정책이 여성의 노동시장 참여에 미치는 영향은 제한적일 수밖 에 없다. 따라서 최초 경력단절 후 복귀한 뒤 다시 노동시장에 서 이탈하게 되는 경력 재단절에 대한 분석 역시 상당히 중요 하다.

한편, 기존 연구는 주로 미취학 자녀 수나 존재 여부를 설 명변수로 포함하여 자녀 효과를 분석하였다. 그러나 영유아 시 기도 연령에 따라 모(母)의 노동공급 결정에 다른 영향을 줄 수 있다. 자녀연령이 증가하면 유보임금과 보육시설 이용 용이 성이 달라지기 때문이다. 초등학교 입학 시점에서도 큰 변화가 생길 수 있다. 자녀의 초등학교 입학 시기에 학교적응을 돕기 위해 육아휴직 사용을 희망하는 여성들이 많고, 일부는 퇴직을 고려하기도 한다. 이후에도 초등학교 저학년의 경우 이른 하교 시간으로 인해 여성들이 맞벌이에 어려움을 겪는다. 따라서 취 학 자녀를 가진 여성들의 노동공급 결정도 함께 살펴볼 필요 가 있다.

이러한 현실을 반영하여 본 논문에서는 자녀 연령이 여성의 경제활동 참여에 미치는 영향을 경력 재단절에 초점을 맞추어 살펴보고자 한다. 또한, 기존 연구와 달리 최초 복귀 이후 경 력 재단절로 이어지는 장기간의 일자리 변화를 살펴보려고 한 다. 이를 위해 1차 19차 노동패널 자료를 사용하여 여성의 경 력 재단절 요인을 생존분석(Survival Analysis)모형으로 탐구한 다. 분석 시기는 구직시점을 기준으로 경제활동 복귀 이후 비 경제활동 상태로의 전환까지 확대한다. 한편, 선행 연구에서 사용한 자녀 변수의 한계점을 고려하여, 본 연구에서는 미취학 연령에 한정하지 않고, 만 0 세에서 9 세까지 자녀 연령 더미를 사용하여 자녀 나이가 모(母)의 노동공급 결정에 미치는 영향 을 분석한다.

\section{Literature Review}

경제학자들은 결혼, 임신, 출산과 같은 생애사건이 여성의 경제활동참여에 미치는 영향을 다양한 방법으로 연구해 왔다. 출산과 노동공급은 동시에 결정될 수 있기 때문에, 인과효과를 알기 위해 내생성을 통제해야 한다. 도구변수(Instrumental Variable)를 사용한 Angrist and Evans(1998)의 연구 이후, 준 실험(quasi-experiment) 방법을 사용한 다양한 연구가 이루어 졌다.

Angrist and Evans (1998)는 두 자녀의 성별이 동일한 경우 를 도구변수로 사용하여 출산이 부모의 노동공급에 미치는 영 향을 분석하였다. 첫째와 둘째 자녀의 성별이 같으면, 부모들 이 성별이 다른 자녀를 갖기 위해 셋째 자녀 출산을 계획하는 경향을 도구변수로 활용한 것이다. 분석 결과 출산은 여성의 노동공급을 감소시켰다. 그러나 기존 최소제곱추정(OLS) 결과 와 달리, 대학을 졸업한 여성이나 남편의 소득이 높은 경우 출 산이 노동공급에 큰 영향을 주지 않았다. 최근 연구에서 Lundborg, Plug, and Rasmussen(2017)은 시험관아기 시술을 도구변수로 사용하여, 출산과 노동공급의 인과관계를 분석하였 다. 첫 시술 만에 인공수정에 성공한 경우, 단기적으로 근로시 간이 감소하였으나 장기적으로 경제활동 참여율에 미치는 영 향은 적었다. 반면, 출산은 장기적으로 소득에 부정적인 효과 가 있었는데, 이는 저임금이나 시간제 일자리, 근거리 직장으
로 여성들이 이직하는 현상과 관련있었다.

미국은 60 년대 후반부터 20 대 초반 미혼여성들에게 경구피 임약 사용을 허용하였다. Goldin and Katz(2002)와 Bailey (2006)는 정책도입 시기 전후를 비교하여 출산 효과를 간접적 으로 살펴보았다. Goldin and Katz(2002)에 의하면 피임약의 보급으로 여성의 초산연령이 증가하고, 대졸 여성들의 전문과 정 진학률도 상승하였다. 준 실험방법을 사용한 Bailey(2006) 의 연구에서 피임약 허용 연령의 확대는 22세 이전에 첫 출산 할 가능성을 낮추고, 여성의 유급노동시장 참여와 연간 근로시 간을 증가시켰다. 자녀의 생애시기별로 여성의 근로시간을 분 석한 Paull(2008)의 연구에서는 첫 출산 후 근로시간이 가장 크게 감소하였다. 여성의 생애주기사건과 노동공급의 관계를 살펴본 Jeon(2008)의 연구에서도 출산이 노동시장 이탈과 가 장 큰 관련이 있었다.

출산과 달리 자녀 양육은 보육대행자나 보육시설 이용을 통 해 여성의 역할을 대체할 수 있다. 기혼여성의 경제활동참여를 독려하기 위한 정책으로 크게 보육비 지원과 보육시설 확충이 있다. 보육비 지원정책이 여성의 노동공급에 미치는 영향에 대 해서는 의견이 분분한데, 국가의 상황이나 정책에 따라 효과가 다르게 나타나기 때문이다. 초기 연구로 Heckman(1974)은 근 로장려정책과 결합된 보육 바우처 도입과 세액공제 혜택이 여 성의 노동공급에 미치는 영향을 살펴보았다. 보육 바우처는 공 식 탁아시설에 자녀를 보낼 경우에만 사용할 수 있다. 따라서 기존에 가족 돌봄과 같이 비공식적인 보육방법을 사용했던 여 성들이 공식 보육시설에 자녀를 맡김으로써 궁극적으로 보육 비용이 증가하고 무차별곡선이 이동한다. 반면, 세액공제 혜택 은 임금률 상승효과를 주기 때문에 예산제약식의 기울기가 변 한다. 따라서 Heckman(1974)은 두 제도가 동시에 도입될 때 노동공급에 미치는 최종 효과는 세액공제 혜택으로 임금률이 얼마나 상승하는지에 달려있다고 보았다. Klerman and Leibowitz(1990)의 연구에서는 보육비에 대한 세액공제혜택이 보육방식에 상관없이 출산 3 개월 후에 복귀할 가능성을 높이 지만, 장기적 효과는 크지 않았다.

보편적 보육정책(universal childcare) 도입의 효과에 대해서 도 연구가 이루어졌다. 보편적 보육정책은 보육시설을 이용할 때 가구소득이나 모(母)의 근로여부에 상관없이 일정액의 보육 비를 지원한다. 캐나다 퀘벡에서는 보편적 보육제도 도입으로 보육시설 이용과 모(母)의 노동공급이 모두 증가하였다(Baker, Gruber, \& Milligan, 2008; Haeck, Lefebvre, \& Merrigan, 2015). 반면, 노르웨이는 보육보조금을 3 6세까지 확대하였는 데 비공식적 보육(informal childcare)에 대한 구축효과만 나타 났고 여성 고용률은 증가하지 않았다(Havnes \& Mogstad, 2011). 스웨덴은 보편적 보육정책 도입 후 보육비 상한제를 시행하였으나 추가적인 보육비 인하는 노동공급에 영향을 주 지 않았다(Lundin, Mörk, \& Öckert, 2008).

자녀의 취학효과에 대한 선행연구도 이루어졌다. Paull (2008)은 자녀성장시기별 어머니의 근로시간변화를 살펴보았 다. 분석결과 초등학교에 입학하는 자녀가 있을 때 전일제 일 자리로 취업할 확률이 가장 낮았다. 반면, Jeon(2008)의 연구 에서는 자녀의 취학이 어머니의 취업이나 재취업에 영향을 주 지 않았다. Gelbach(2002)는 자녀의 생일이 속하는 분기에 따 라 공립학교 등록시기가 달라지는 점을 이용하여, 공립학교 이 용이 어머니의 노동공급에 미치는 영향을 살펴보았다. 연구결 과를 보면, 자녀의 공립학교 입학으로 어머니의 노동공급이 증 가하고, 정부보조를 받는 편모가정의 수가 감소하였다. 
경력단절 여성에 대한 기존 연구에는 몇 가지 한계점이 있 다. 우선, 자녀를 취학연령과 미취학연령으로 구분하기 때문에 초등학교 입학 시기의 특수성을 고려하지 못한다. 이분법적으 로 자녀연령을 구분하면 초등학교 입학 시기의 특수성을 고려 하지 못한다. 앞서 언급한 바와 같이 자녀의 학교 적응을 돕기 위해 초등학교 입학 시기에 여성들이 휴직이나 퇴직을 고려하 는 경우가 드물지 않다. 또한, 초등학교 저학년 하교 시간이 이르기 때문에 만 7 세 시기는 맞벌이 여성들의 노동공급 결정 에 영향을 줄 가능성이 높다. 따라서 초등학교 입학 시기의 특 수성을 간과한 채 취학연령으로 구분할 경우 해당 시기의 효 과를 제대로 파악하기 어렵다. 한편, 패널 자료를 사용한 기존 연구는 주로 단절 혹은 복귀 중 한 가지 연구만 수행하여, 경 력단절 이후 복귀 혹은 복귀 이후 재단절 여부에 대해 알 수 없다.

본 연구는 다음과 같은 점에서 기존 연구와 다르다. 첫째, 자녀 연령 더미를 주요 설명변수로 사용하였다. 본 논문은 내 생성 문제를 줄이기 위해 자녀 수 대신 연령대별 자녀 더미를 사용하였다. 자녀 나이의 증가가 여성의 노동공급에 영향을 줄 수 있으나 역인과관계는 존재할 수 없기 때문이다. 자녀 연령 더미를 사용하기 때문에 미취학과 취학 자녀로 구분하지 않는 다. 두 번째, 본 연구는 노동패널 1 19차 자료를 사용하여, 여 성들의 첫 경력단절과 복귀 이후에 재단절에 자녀의 나이가 미치는 영향을 분석하였다.

\section{Methodology}

\section{1. 이론적 배경}

한정된 시간과 임금률로 결정되는 예산제약하에서 개인은 효용을 극대화하는 최적의 여가와 소비수준을 결정한다. 임금 률이 노동공급에 미치는 영향은 크게 두 가지로 구분된다. 먼 저 임금률의 상승은 여가의 비용을 높여 상대적으로 비싼 여 가의 소비를 줄이고, 노동공급을 늘리는 대체효과를 발생시킨 다. 한편, 임금률의 상승은 소득을 증가시키는데, 여가를 정상 재라고 할 때, 소득이 오르면 여가는 증가하고 노동공급은 감 소한다. 즉, 소득효과는 노동공급을 줄이는 방향으로 나타난다. 따라서 임금률 상승이 노동공급에 미치는 영향은 두 효과의 상대적인 크기로 결정되며, 노동공급 곡선은 이른바 후방굴절 (backward bending) 형태로 나타난다.

기혼 여성의 노동공급은 이러한 기본 모형에서 추가적인 요 소를 고려한다. Mincer(1962)에 따르면, 소비행동의 분석단위 는 개인이 아닌 가족이 된다. 즉, 부부의 소득을 합친 가구소 득이 예산제약이 되며, 여가와 근로시간, 가사노동시간의 분배 는 단순히 개인의 선호, 절대적인 임금수준이 아니라 구성원의 상대적인 가격에 의해 결정된다. 예를 들어, 미혼자의 임금이 상승하면, 최종적인 노동공급의 변화는 대체효과와 소득효과의 상대적인 크기로 결정된다. 반면, 기혼자의 임금 상승은 당사 자의 노동공급 결정 외에 배우자의 노동공급에도 영향을 준다. 부부가 모두 일할 경우, 임금이 상승한 사람의 여가비용이 상 대적으로 증가한다. 따라서 여가비용이 상대적으로 비싼 사람 은 노동공급을 더 늘리고, 배우자는 노동공급을 줄인다.

Becker(1985)는 에너지 소비와 비교우위 개념을 통해 기혼 여성의 노동공급을 설명한다. 여성의 경우 육아와 일을 이중으
로 부담하기 때문에 한정된 에너지를 가사와 근로에 나누어 사용한다. 육아는 다른 가사노동에 비해 힘이 많이 들기 때문 에(effort intensive), 여성은 육아에 필요한 에너지를 비축하기 위해 노동시장에서 남성보다 시간당 에너지를 적게 사용한다. 그 결과, 기혼남성에 비해 기혼여성의 상대적 시급이 감소한 다. Becker(1985)는 소득 감소가 기혼여성의 경제활동참여 의 욕을 더욱 저하시키고, 저투자, 저소득, 저의욕의 순환이 남녀 임금격차와 직종 분리현상(job segregation)을 유발할 뿐 아니 라, 노동시장 탈퇴로 이어질 수 있다고 보았다.

오늘날에는 가사와 육아에 참여하는 남성이 증가하고 있으 나, 여전히 육아에서 여성의 몫이 큰 편이다. 따라서 여성들은 결혼 후 가사(육아), 여가, 근로 수준을 결정하게 되며, 특히 자녀 나이와 자녀 수에 따라 근로의 기회비용이 달라진다. 이 러한 특성을 고려하면, 기혼여성의 노동공급 결정은 다음과 같 이 나타낼 수 있다. 이하의 이론 모형을 전개하는 과정에서 Gwon(2015), Yao and Kwak(2017) 등도 참고하였다.

$$
\begin{aligned}
& C=w(T-L)+I_{n}=w h+I_{n} \\
& C \text { 소비, } w \text { 시간당임금 }\left(w>w_{r}\right), \\
& T \text { 전체가용시간, } L \text { 여가시간, } h \text { 근로시간 }(=T-L), I_{n} \text { 비근로소득 }
\end{aligned}
$$

소비 혹은 총소득은 크게 근로소득과 비근로소득으로 구분 되며, 근로소득은 시간당임금과 근로시간의 곱이다. 임금이 유 보임금 $\left(w_{r}\right)$ 보다 클 때 노동시장에 진입하기 때문에 근로소득 은 유보임금보다 큰 경우에만 존재한다. 비근로소득 $\left(I_{n}\right)$ 은 다시 배우자의 소득 $\left(I_{h s}=w_{h s} h_{h s}\right)$ 과 가구전체 비근로소득 $\left(I_{h h n}\right)$ 으로 구성된다 $\left(I_{n}=w_{h s} h_{h s}+I_{h n n}\right)$. 효용은 소비와 정상재인 여가시 간의 함수이며, 여가시간에는 가족, 자녀와 함께 보내는 시간 이 포함된다.

$$
\begin{aligned}
& U=f(C, L) \\
& U \text { 효용, } L \text { 여가시간(자녀와 함께 보내는 시간포함) }
\end{aligned}
$$

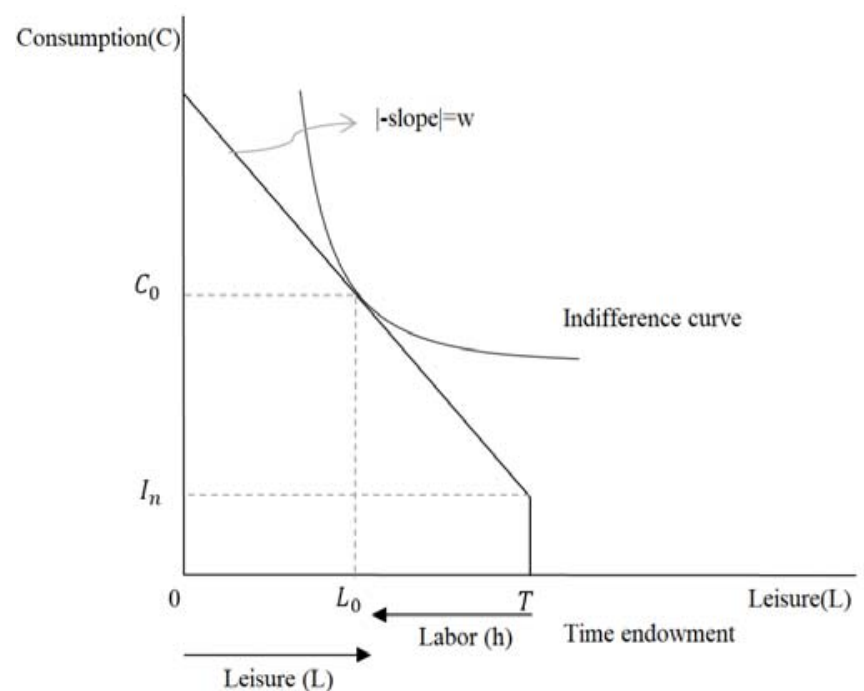




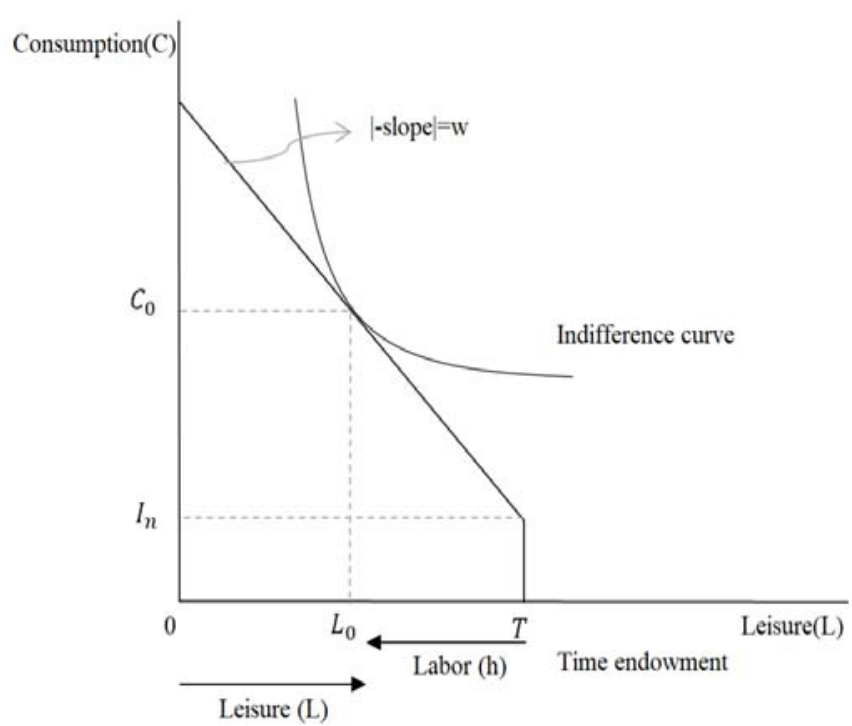

<Figure 1> Married women's labor supply

<Figure 1> 에서 나타나듯, 여성 개인의 임금률은 예산제약 선의 기울기를, 비근로소득은 절편을 결정하며, 균형 노동공급 량(노동시간)은 예산제약하에서 효용을 극대화하는 점이다. 한 편, 기혼여성의 경제활동참가율 변화는 수요와 공급곡선의 이 동으로 설명한다. Goldin(1992)에 의하면, 선호의 변화, 가족부
양의무, 가사노동에 소요되는 비용의 감소, 가구소득의 변화, 근로조건의 변화로 노동공급이 변한다. 한편, 기술의 변화, 정 규교육, 근로분야의 변화, 고용주와 근로자의 선호 변화는 기 혼여성에 대한 노동수요에 영향을 준다.

Goldin and Mitchell(2017)은 노동참여율 변화를 세 가지 효 과로 설명하였다. 먼저 기간 효과(Period effects)는 전쟁이나 경기침체와 같이 연령에 상관없이 모든 개인에게 영향을 준다. 두번째로 코호트 효과(Cohort effects)는 생애주기 노동참여율 함수의 절편을 결정한다. 코호트는 서로 형태가 유사하지만 코 호트 효과에 따라 높이가 다르다. 마지막으로 생애주기 효과 (Lifecycle effects)는 결혼연령, 초산 연령에 따른 변화를 반영 하여 노동참여율 함수의 모양을 결정한다.

예를 들어 <Figure 2>를 보면, 우리나라 여성의 연령대별 경제활동 참가율은 2000년과 2016년 모두 M자형을 보이고 있 다. M자형 경제활동 참여율은 생애주기 효과로 설명할 수 있 다. 즉, 결혼, 출산, 육아 등 다수의 여성들이 공통적으로 경험 하는 생애사건들은 노동공급에 영향을 주기 때문에 모든 연도 에서 해당 시기에 경제활동참여율이 감소한다. 반면, 2000년과 2016년을 비교하면, 기본 패턴은 유사하지만, 20대 이상에서 여성의 경제활동 참여율이 더 높게 나타난다. 이러한 곡선자체 의 상향 혹은 하향 이동은 출생 코호트 효과로 설명할 수 있 다. 본 논문에서는 생애주기 효과에 주목하여 여성의 노동참여 율 변화를 살펴본다. 주요 변수인 만0세부터 9 세까지 자녀나 이 더미를 통해 출산, 육아, 자녀의 취학시기가 여성의 경제활 동참여 결정에 미치는 영향을 알 수 있다.

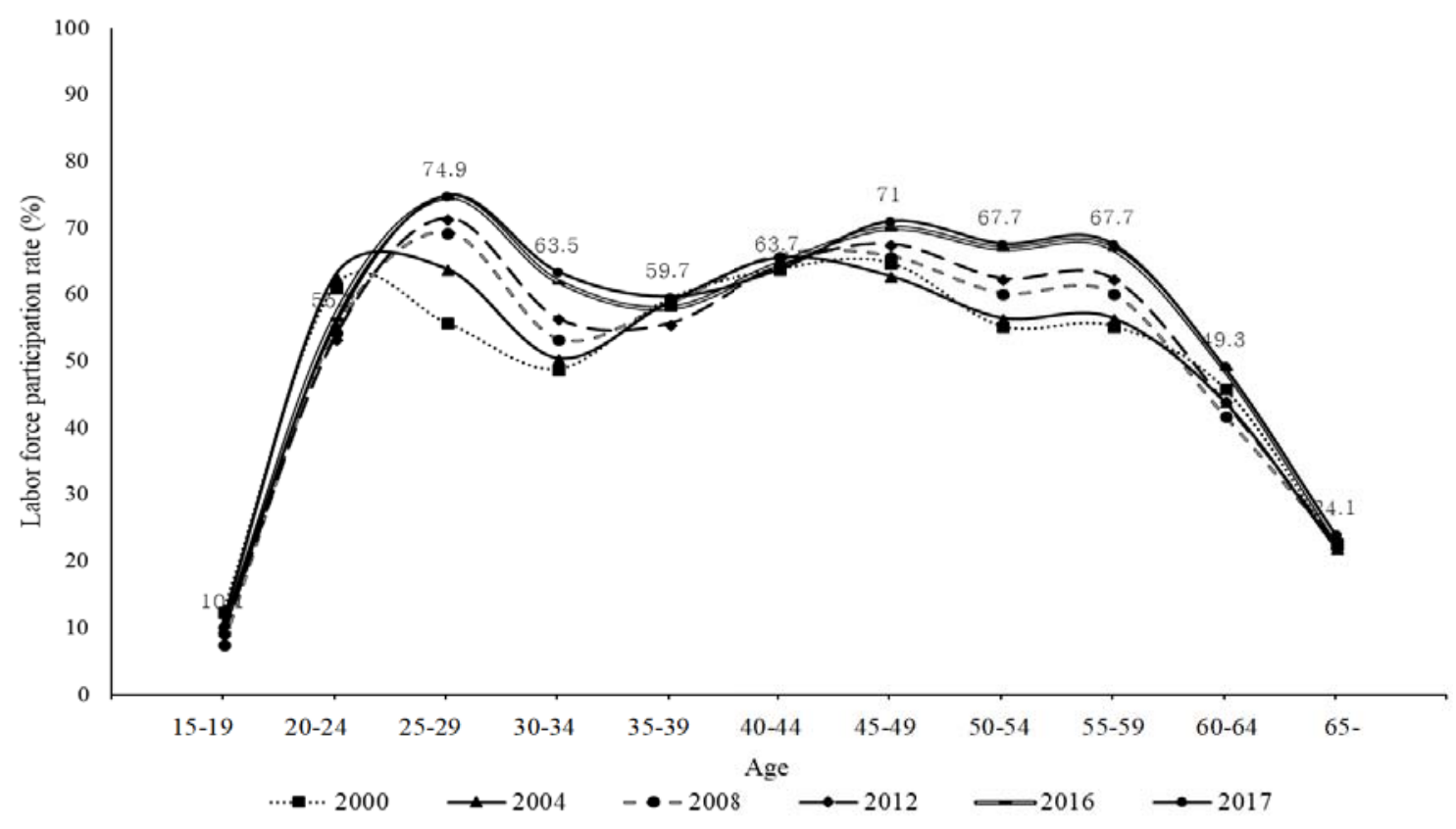




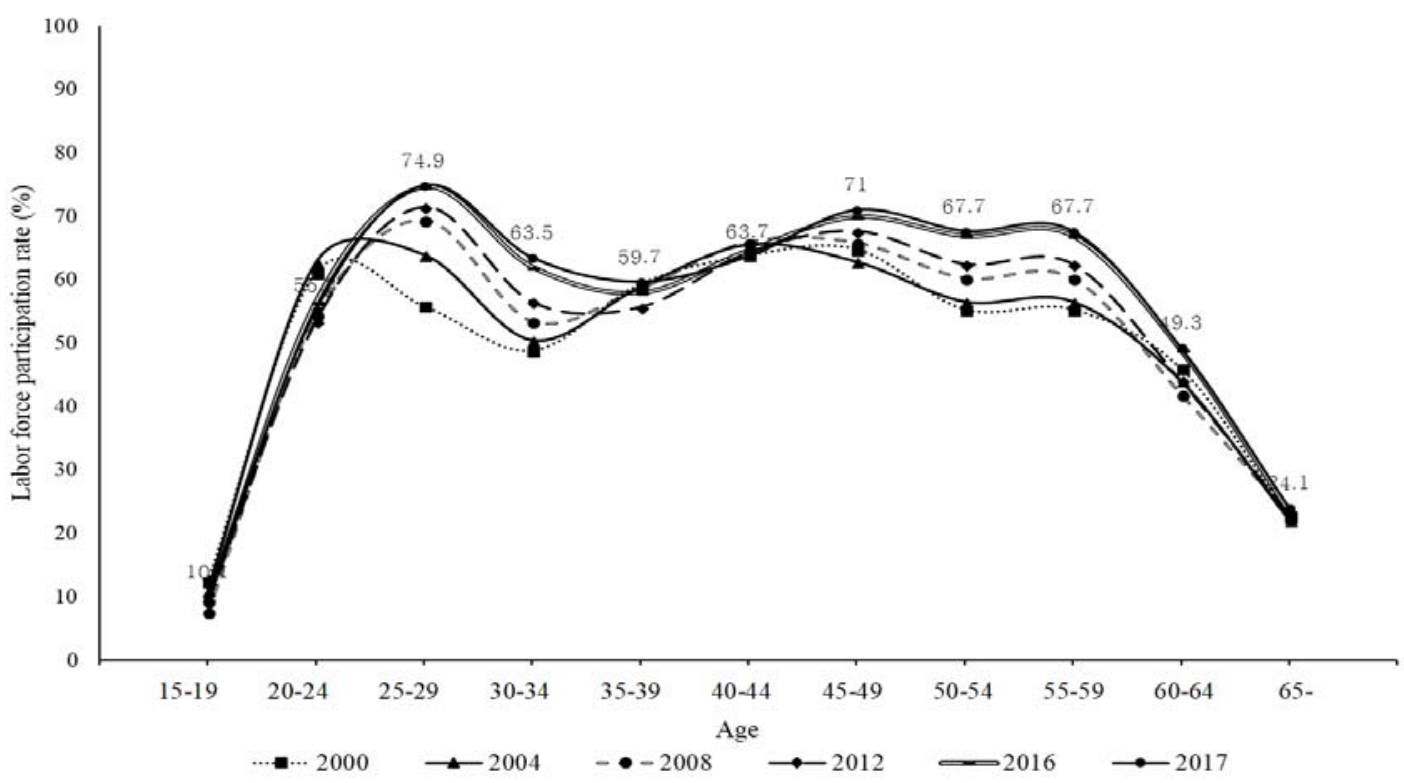

Source: Statistics Korea(2017a).

<Figure 2> Women's labor force participation rate

\section{2. 분석모형}

생존분석(survival analysis)은 사건 발생까지의 시간(timeto-event)을 분석하는 모형이다. 생존분석방법의 특성을 알기 위해 먼저 절단(censoring)에 대한 이해가 필요하다.
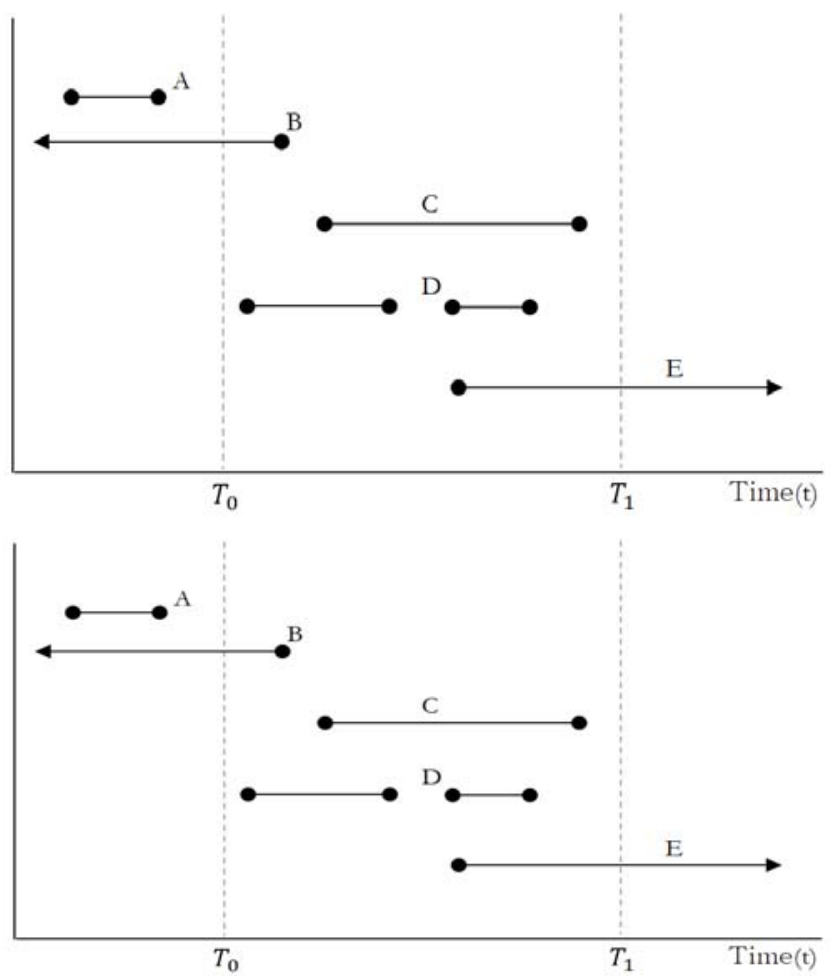

$<$ Figure 3> Spells of survival analysis
근로 혹은 실업기간을 패널데이터로 살펴보면, <Figure 3> 에서 나타나듯 시작과 종료시점에 따라 다양한 형태의 데이터 가 존재한다. 분석 기간을 $\mathrm{T} 0$ 에서 $\mathrm{T} 1$ 까지로 설정할 경우, 생 존분석을 위해 C, D, E만 사용할 수 있다. C와 D는 분석기간 중에 관찰이 시작되고 사건발생으로 기간이 종료되었으므로 분석이 가능하다. 반면, $\mathrm{B}$ 는 좌측절단(left-censored)기간으로, 시작시점을 알 수 없기 때문에 정확한 기간(spell)을 파악하는 것이 불가능하다. 또한, $\mathrm{A}$ 와 같은 회고자료는 해당하는 시기에 개인의 특성을 아는 경우에만 생존분석에 사용할 수 있다. $\mathrm{E}$ 는 관찰이 시작되었으나 아직 사건(혹은 실패)이 발생하지 않 은 우측절단(right-censored) 기간에 해당한다. 이는 사건발생 으로 인한 실패(이탈)와 다르기 때문에 구분할 필요가 있다.

본 논문에서 사용하는 노동패널 1차 19차(1998년 2016년) 자료를 예로 들면, 회고적 일자리는 $\mathrm{A}$ 에 해당하므로 생존분석 에서 제외된다. TO전에 이미 종료된 회고적 일자리(A)는 취업 당시 개인의 특성을 파악할 수 없기 때문이다. 1998년 이전에 시작되었으나 조사시점까지 진행 중인 일자리는 좌측절단(B) 의 예이며, $\mathrm{A}$ 와 마찬가지 이유로 분석에서 제외한다. 우측절단 은 경력단절과 복귀분석에서 다르게 정의된다. 경력 재단절에 대한 생존분석에서는 취업 후 종료시점(T1)까지 근로 중이면 우측절단(E)에 해당한다. 본 논문에서는 경제활동참여시점을 기준으로도 동일한 분석을 하였는데, 구직활동 시점이 존재하 는 경우 재취업시점 대신 구직활동시점을 사용하였다. 경제활 동인구에서 다시 이탈하는 경우는 크게 3가지 유형으로 기간 이 종료되는데, (1) 재취업 후 다시 단절, (2) 구직활동을 통해 경제활동인구에 다시 편입되었으나 취업실패 후 구직활동을 종료, (3) 아직 구직 중이거나 재취업 후 계속 근로중인 우측 단절이 있다. <Table $1>$ 은 경력 재단절 분석, 경제활동 재이탈 분석의 시작과 종료 시점을 보여준다. 
$<$ Table 1> Beginnings and ends of study periods

\begin{tabular}{|c|c|c|}
\hline $\begin{array}{c}\text { Types of } \\
\text { hazard }\end{array}$ & T0(month and year) & T1(month and year) \\
\hline $\begin{array}{c}\text { Quitting a } \\
\text { job }\end{array}$ & $\begin{array}{c}\text { The date of new } \\
\text { employment after the } \\
\text { first career interruption }\end{array}$ & The date of quitting a job. \\
\hline $\begin{array}{c}\text { Exit from } \\
\text { the labor } \\
\text { force }\end{array}$ & $\begin{array}{c}\text { The date of labor } \\
\text { market participation } \\
\text { after the first career } \\
\text { interruption. }\end{array}$ & $\begin{array}{c}\text { (1) } \begin{array}{l}\text { The last date of job } \\
\text { search. }\end{array} \\
\text { (2) The date of quitting a job. }\end{array}$ \\
\hline
\end{tabular}

일반적인 선형회귀방법 대신 생존분석 모형을 사용하는 이 유는 다음과 같다. 첫째, 최소제곱추정(OLS)방법에서 오차항이 정규분포를 따른다는 가정이 현실과 맞지 않는다(Cleves, 2008). 위험함수는 비대칭 형태일 가능성이 높기 때문이다. 둘 째, 로짓, 프로빗 모형은 경력단절이나 복귀 여부를 구분할 수 있으나, 개인마다 다른 단절/복귀 시기를 고려하지 못한다. 셋 째, Go and $\operatorname{Kim}(2017)$ 등에서 지적한 선형회귀분석에서 발생 할 수 있는 편의(bias)문제를 해결할 수 있다. 선형모형은 데이 터의 절단(censoring)과 사건발생으로 인한 이탈(exit)을 구분하 지 못한다. 그러나, 절단은 사건이 발생하지 않은 채로 조사가 종료된 것이므로 이탈에 포함할 경우에는 과대 추정될 여지가 있고, 분석에서 제외할 경우에는 과소 추정될 수 있다.

Kiefer(1988)를 바탕으로 생존분석모형을 간단히 설명하면 다음과 같다. 월 단위의 생존기간을 나타내는 확률변수 $\mathrm{T}$ 의 누적분포함수 $(\mathrm{F}(\mathrm{t}))$ 와 확률밀도함수 $(\mathrm{f}(\mathrm{t}))$ 는 다음과 같이 정의한 다.

$$
\begin{aligned}
& F(t)=\operatorname{Pr}(T<t) \\
& f(t)=\lim _{\Delta t \rightarrow 0} \operatorname{Pr}(t \leq T \leq t+\Delta t) / \Delta t=\partial F(t) / \partial t
\end{aligned}
$$

생존함수(survival function)는 생존기간이 $\mathrm{t}$ 기 이상일 확률로, $\mathrm{t}=0$ 일 때 생존확률이 1 이며, 시간이 지날수록 생존확률은 0 으 로 수렴한다.

$$
\begin{aligned}
& S(t)=1-F(t)=\operatorname{Pr}(T \geq t) \\
& S(0)=1, \quad \lim _{t \rightarrow \infty} S(t)=0
\end{aligned}
$$

위험함수(hazard function)는 $\mathrm{t}$ 기까지 생존했을 때, $\mathrm{t}$ 에서 생 존기간이 종료되는(즉, 실패하는) 비율로 다음과 같이 표현되 며, 이에 상응하는 누적위험함수는 $H(t)$ 로 표현한다.

$$
\begin{aligned}
& h(t)=\lim _{\Delta t \rightarrow 0} \operatorname{Pr}(t \leq T \leq t+\Delta t \mid T \geq t) / \Delta t=f(t) / S(t)=f(t) / 1-F(t) \\
& H(t)=\int_{0}^{t} h(u) d u
\end{aligned}
$$

생존분석에서 위험함수는 중요한 개념으로 확률밀도함수와 구분할 필요가 있다. 예를 들어 확률밀도함수 $f(24)$ 는 퇴직 하 였을 때, 24 개월째에 재취업하게 될 확률을 의미한다. 반면, 위험함수 $h(24)$ 는 퇴직한 지 24개월이 된 상황에서 정확히 24 개월째에 다시 취업하는 비율이다. 즉, 경력단절 2 년후에 복귀
할 확률은 기존의 선형모형으로도 알 수 있으나, 생존분석에서 는 위험함수를 통해, 경력이 단절된 지 2년째인 사람이 해당 시점에서 복귀할 확률이 얼마나 되는지 알 수 있다.

생존분석은 기저위험함수(baseline hazard function)의 형태 를 가정하는지에 따라 모수모형(parametric model)과 비모수모 형(nonparametric model), 준모수모형(semi-parametric model) 의 세 가지가 있다. 본 연구에서는 콕스비례위험모형(Cox proportional hazard model, 이하 콕스모형)을 이용하였다. 모 수모형은 해석이 용이한 가속실패시간모형(Accelerated Failure Time model, 이하 AFT모형)으로 변환할 경우, 추정된 계수 값 을 통해 생존시간에 대한 보다 직관적인 해석이 가능하다. 그 러나 가정한 기저위험함수의 분포가 실제 분포와 맞지 않을 수 있기 때문에, 함수형태에 대한 가정이 필요하지 않은 준모 수 혹은 비모수 모형이 더 적절할 수 있다.

개인특성벡터 $(\mathrm{X})$ 를 강조하기 위해 위험함수를 다음과 같이 표현할 수 있다.

$$
h(t, X)=\alpha t^{\alpha-1} \exp \left(\beta^{\prime} X\right)=h_{0}(t) \exp \left(\beta^{\prime} X\right)=h_{0}(t) \lambda
$$

만약 시간이 일정하고, $\mathrm{X}$ 만 다르다면 $\left(t=\bar{t}, \mathrm{X}_{\mathrm{i}} \neq \mathrm{X}_{\mathrm{j}}\right) \bar{t}$ 에서 두 위험함수의 차이는 다음과 같이 비율로 표현된다.

$$
h\left(\bar{t}, X_{i}\right) / h\left(\bar{t}, X_{j}\right)=\exp \left(\beta^{\prime} X_{i}\right) / \exp \left(\beta^{\prime} X_{j}\right)=\exp \left(\beta^{\prime}\left(X_{i}-X_{j}\right)\right)(1)
$$

즉, 기간이 동일하고 $\mathrm{X}$ 특성만 다를 경우, 위험비율(hazard ratio)은 $\exp \left(\beta^{\prime}\left(\mathrm{X}_{\mathrm{i}}-X_{j}\right)\right)$ 만큼 변하게 된다. 만약 동일한 특성 $(\mathrm{Xi})$ 이 한 단위만 증가한다고 가정하면 식(1)은 다음과 같이 표 현되고, $X i$ 가 한 단위 증가할 때, 위험비율이 $\mathrm{e}^{\beta_{i}}$ 만큼 변한다고 해석한다.

$$
\left.h\left(\bar{t}, X_{i}+1\right) / h\left(\bar{t}, X_{i}\right)=\exp \left(\beta_{i}^{\prime}\left(\left(X_{i}+1\right)-X_{i}\right)\right)\right)=\exp \left(\beta_{i}\right)
$$

모수 $(\beta)$ 를 추정하는 방법에서 모수모형과 콕스모형은 차이 가 있다. 모수모형은 개인의 생존확률을 모두 곱하여 최우추정 법을 이용해 실제 자료와 가장 일치하는 모수의 값을 추정한 다. 콕스모형은 각 실패시점에서의 조건부 실패확률을 곱하여 모수값을 추정하는 부분우도법(partial likelihood)을 사용한다. 예를 들어, $\mathrm{N}$ 명의 사람이 한 번에 한 명씩만 실패한다고 가정 하고, 실패시간(t)이 이른 순서대로 $\mathrm{t} 1$ 에서 $\mathrm{tn}$ 로 정의하면 부분 우도는 다음과 같이 표현된다.

$$
\begin{aligned}
& \left.\left.L=L_{1}\left(\text { fail at } t_{1}\right) L_{2} \text { (fail at } t_{2}\right) \cdots L_{n} \text { (fail at } t_{n}\right) \\
& =\prod_{j=1}^{n} L_{j} \quad j=1,2, \ldots n \\
& =\prod_{\mathrm{j}=1}^{\mathrm{n}}\left(\lambda_{\mathrm{i}}\left(\beta, \mathrm{X}_{\mathrm{i}}\left(\mathrm{t}_{\mathrm{j}}\right)\right) / \sum_{\mathrm{i} \in S\left(\mathrm{t}_{\mathrm{j}}\right)} \lambda_{\mathrm{i}}\left(\beta, \mathrm{X}_{\mathrm{i}}\left(\mathrm{t}_{\mathrm{j}}\right)\right)\right)^{\mathrm{d}_{\mathrm{i}}} \\
& \mathrm{j}=1,2, \ldots, \mathrm{n} \text { 실패시기 (이른순서 대호) } \\
& i=1,2, \ldots, N \text { 개인 }
\end{aligned}
$$


$\mathrm{X}_{\mathrm{i}}\left(t_{j}\right): \quad t_{j}$ 시기에 $i$ 라는 사람의 개인톡성 벡터

$s\left(\mathrm{t}_{\mathrm{j}}\right): t_{j}$ 기 직전까지 살아남은 $i$ 들의 집합.

$d_{i}=1$ 실패학경우, $d_{i}=0$ 우촉절 단

\section{3. 자료}

기혼여성의 경제활동 참여에 자녀 나이가 미치는 영향을 분 석하기 위해 부모와 자녀를 연결하고, 자녀의 만 나이를 계산 하였으며, 취업과 퇴직, 구직 시점 정보를 사용하였다. 부모와 자녀를 연결하기 위해 노동패널 1 19차 자료를 모두 사용하였 으나, 주요 설명변수인 가계부채가 1차에서 조사되지 않았기 때문에, 1999년 이후에 시작된 일자리만 고려했다. 분석대상은 경제활동인구조사 기준에 맞추어 만 15 54세 여성으로 정했 다. 또한 퇴직 시기에 만 0 12세 자녀가 한 명이라도 있었던 여성을 표본으로 하였다. 따라서 여러 차례 퇴직을 하였으며, 한 번이라도 퇴직 당시 만 0 12세 자녀가 있었던 여성이 분석 대상이다.

주요 변수의 기술통계량은 <Table 2>에 제시했다. 분석에는 나이, 교육연수, 자녀나이, 남편 일자리, 입직 당시 일자리에 관한 변수를 사용했다. 자녀나이 더미는 18세 이하 자녀가 있 는 경우 0 의 값을 가지며, 만 0 세 9 세에 해당하는 자녀가 있 으면 1이 된다. 따라서 추정계수는 만 18세 이하 다른 연령대 자녀가 있는 경우에 비해, 특정 연령(만 0 9세)의 자녀가 있을 때 생존시간 변화로 해석한다.

자녀 수 더미는 만 7 세 이하 자녀수가 2 명 이상이면 1 의 값을 가지며, 1 명 이하인 경우 0 의 값인 더미변수로 통제하였 다. 미취학연령인 만 6 세를 상한으로 설정하여도 결과에 변함 은 없으나, 본 연구에서는 초등학교 입학시기가 어머니의 노동
공급결정에 중요한 영향을 준다고 가정하기 때문에 기준연령 을 만 7세로 설정하였다.

남편 임금 이외의 비근로 소득이나 자산을 통제하기 위해 가구부채를 사용했다. 가구자산의 경우, 높은 비중을 차지할 것으로 예상되는 주택가격에 범주형 응답이 혼재되어 있다. 따 라서 가구자산 대신 직접 값을 기재하는 가구부채 변수를 사 용했다. 전체 표본의 $47 \%$ 가 가구부채가 0 이라고 응답했고, 분 석에는 가구부채액을 십제곱근 $\left(x^{1 / 10}\right)$ 으로 조정하여 사용했다. 남편의 일자리 정보는 본업과 부업을 합친 것으로, 시간당 임 금(만 원)은 2015년 기준 실질임금이며, 주당 총근로시간은 5 시간 단위로 조정했다.

\section{Results}

<Table 3> 은 생존시간을 경력단절 여성의 재취업시점부터 다시 경력단절을 경험할 때까지의 근로기간으로 정의하여 분 석한 결과이다. 1,175 개 관측치(332명) 중 100 명이 복귀 후 다 시 경력단절을 경험하였다. 전체모형에서 여성의 나이가 한 살 증가할 때, 경력단절 확률은 약 $5 \%$ 감소한다. 그러나 출산 유 형만 살펴보았을 때는 관측치 수가 줄어들면서 여성의 나이에 대한 추정계수의 표준오차가 증가했다. 첫 단절과 마찬가지로, 자녀가 만 0 세일 때 경력단절 확률은 자녀가 만 10 18세일 때보다 약 3.6배 높다. 출산 후 자녀가 성장하면서 어머니의 노동공급에 미치는 영향은 점차 감소하지만, 만 3세와 7세 시 기에 위험비율이 크게 증가하여 여성들은 경력지속에 위기를 겪게 된다. 자녀가 만 9 세가 되면, 추정계수의 부호가 바뀌지 만 표준오차가 커서 경력단절 위험이 낮아진다고 단정하기는 어려웠다.

<Table 2> Descriptive statistics

\begin{tabular}{|c|c|c|c|c|c|c|c|c|}
\hline \multirow[b]{2}{*}{ Variables } & \multicolumn{4}{|c|}{ Quitting a job } & \multicolumn{4}{|c|}{ Exit from the labor force } \\
\hline & Mean & Standard Deviation & Minimum & Maximum & Mean & Standard Deviation & Minimum & Maximum \\
\hline Age & 34.70 & 5.50 & 21.00 & 55.00 & 39.55 & 6.27 & 23.00 & 58.00 \\
\hline Years of education & 13.62 & 1.98 & 3.00 & 22.00 & 12.88 & 2.16 & 6.00 & 22.00 \\
\hline 0 -year-old child $=1$ & 0.15 & 0.36 & 0.00 & 1.00 & 0.03 & 0.16 & 0.00 & 1.00 \\
\hline 1-year-old child $=1$ & 0.16 & 0.37 & 0.00 & 1.00 & 0.04 & 0.21 & 0.00 & 1.00 \\
\hline 2-year-old child $=1$ & 0.15 & 0.36 & 0.00 & 1.00 & 0.07 & 0.25 & 0.00 & 1.00 \\
\hline 3-year-old child $=1$ & 0.14 & 0.35 & 0.00 & 1.00 & 0.08 & 0.26 & 0.00 & 1.00 \\
\hline 4-year-old child $=1$ & 0.13 & 0.34 & 0.00 & 1.00 & 0.08 & 0.27 & 0.00 & 1.00 \\
\hline 5-year-old child $=1$ & 0.12 & 0.32 & 0.00 & 1.00 & 0.08 & 0.28 & 0.00 & 1.00 \\
\hline 6 -year-old child $=1$ & 0.10 & 0.31 & 0.00 & 1.00 & 0.09 & 0.29 & 0.00 & 1.00 \\
\hline 7-year-old child $=1$ & 0.11 & 0.31 & 0.00 & 1.00 & 0.10 & 0.30 & 0.00 & 1.00 \\
\hline 8-year-old child $=1$ & 0.10 & 0.30 & 0.00 & 1.00 & 0.10 & 0.30 & 0.00 & 1.00 \\
\hline 9-year-old child $=1$ & 0.09 & 0.29 & 0.00 & 1.00 & 0.10 & 0.30 & 0.00 & 1.00 \\
\hline $\begin{array}{l}\text { The number of children } \\
\text { under age } 7=1\end{array}$ & 0.30 & 0.46 & 0.00 & 1.00 & 0.14 & 0.35 & 0.00 & 1.00 \\
\hline Household debt & 1.32 & 1.16 & 0.00 & 3.17 & 1.39 & 1.14 & 0.00 & 3.39 \\
\hline $\begin{array}{l}\text { Husband's hourly } \\
\text { wage }(\# \backslash 10,000)\end{array}$ & 1.84 & 1.37 & 0.00 & 22.67 & 1.67 & 1.16 & 0.00 & 14.13 \\
\hline $\begin{array}{c}\text { Husband's weekly } \\
\text { working hours (5hours) }\end{array}$ & 11.78 & 4.85 & 0.00 & 65.80 & 11.66 & 4.78 & 0.00 & 65.80 \\
\hline $\begin{array}{l}\text { Observations } \\
\text { (the number of women in parenthesis) }\end{array}$ & & $2,588(6$ & & & & 802 & & \\
\hline
\end{tabular}

Note: a) A function $y=x^{1 / 10}$ is used instead of log function because $47 \%$ of households have no debt. There is almost no difference in results when the original value of household debt is used.

b) Husband's hourly wage and weekly working hours include main and side jobs. The year 2015 is the base year of husband's hourly wage. 
<Table 4>는 경제활동 복귀 시점부터 비경제활동 인구로 전환까지 생존기간을 분석한 결과이다. 구체적으로 살펴보면, 구직활동을 하였으나 취업에 실패한 사람의 생존기간은 구직 시작시점부터 구직 종료까지의 총 구직기간이다. 구직에 성공 하였지만, 이후 경력단절로 퇴직한 여성의 생존기간은 구직시 작 시점 혹은 취업시점(구직시작 시점에 대한 정보가 없는 경 우)부터 퇴직 시기까지의 근로기간이다. 전체 관측치 1,412 개 (362명) 중 103명이 퇴직 혹은 구직 단념으로 비경제활동인구 로 전환하였으며, 분석결과는 <Table $3>$ 와 유사하다.

여성의 나이가 한 살 증가할 때 비경제활동인구로 전환할 확률은 $5 \%$ 정도 낮아진다. 자녀가 만 0 세일 때, 경제활동에서 이탈하는 확률은 초등학교 고학년 이상 시기에 비해 3 배 이상 높다. 앞서 살펴본 것과 같이 자녀 나이가 증가하면서, 어머니 의 경제활동에 미치는 영향은 감소하지만 만 3세와 7 세 시기 에 일시적으로 크게 증가한다.

<Table 3> Survival analysis result: Quitting a job

\begin{tabular}{|c|c|c|c|}
\hline \multirow{2}{*}{ Variables } & \multicolumn{2}{|c|}{ All } & Subgroup \\
\cline { 2 - 4 } & Model 1 & Model 2 & Model 3 \\
\hline Age & $-0.051^{*}$ & $-0.054^{*}$ & -0.018 \\
& $(0.027)$ & $(0.029)$ & $(0.030)$ \\
\hline Years of education & -0.073 & -0.070 & -0.082 \\
& $(0.056)$ & $(0.057)$ & $(0.062)$ \\
\hline 0-year-old child & $1.425^{* * *}$ & $1.274^{* * *}$ & $1.263^{* * *}$ \\
& $(0.395)$ & $(0.409)$ & $(0.426)$ \\
\hline 1-year-old child & $0.992^{*}$ & $0.896^{*}$ & 0.744 \\
& $(0.511)$ & $(0.496)$ & $(0.513)$ \\
\hline 2-year-old child & $0.773^{*}$ & $0.853^{*}$ & 0.737 \\
& $(0.452)$ & $(0.457)$ & $(0.466)$ \\
\hline 3-year-old child & $0.970^{* * *}$ & $1.071^{* * *}$ & $0.945^{* *}$ \\
& $(0.364)$ & $(0.379)$ & $(0.372)$ \\
\hline 4-year-old child & 0.672 & $0.746^{*}$ & 0.590 \\
& $(0.430)$ & $(0.449)$ & $(0.463)$ \\
\hline 5-year-old child & $0.964^{* * *}$ & $0.890^{* *}$ & $0.725^{*}$ \\
& $(0.360)$ & $(0.363)$ & $(0.375)$ \\
\hline 6-year-old child & $0.662^{*}$ & 0.569 & 0.285 \\
& $(0.384)$ & $(0.387)$ & $(0.406)$ \\
\hline 7-year-old child & $1.045^{* * *}$ & $1.030^{* * *}$ & $0.831^{* *}$ \\
& $(0.310)$ & $(0.318)$ & $(0.342)$ \\
\hline 8-year-old child & 0.406 & 0.400 & 0.337 \\
& $(0.293)$ & $(0.297)$ & $(0.296)$ \\
\hline 9-year-old child & -0.199 & -0.211 & -0.407 \\
& $(0.374)$ & $(0.380)$ & $(0.390)$ \\
\hline The number of & -0.614 & -0.661 & -0.490 \\
children under age 7 & $(0.423)$ & $(0.417)$ & $(0.418)$ \\
\hline Household debt & 0.154 & $0.170^{*}$ & 0.120 \\
& $(0.094)$ & $(0.094)$ & $(0.101)$ \\
\hline Husband's hourly & 0.023 & 0.018 & -0.031 \\
wage & $(0.093)$ & $(0.090)$ & $(0.095)$ \\
\hline Husband's weekly & -0.018 & -0.019 & -0.013 \\
working hours & $(0.026)$ & $(0.026)$ & $(0.027)$ \\
\hline Observations & 1,175 & 1,175 & 820 \\
\hline
\end{tabular}

Note: a) Models include constants. Robust standard errors in parenthesis.

*** $p<0.01{ }^{* *} p<0.05,{ }^{*} p<0.10$

b) Year dummies are included in Model 2 and Model 3.

c) The subgroup is a group of women from the sample who have given a birth to a child during survey years (1998-2016).
$<$ Table 4> Survival analysis result: Exit from the labor force

\begin{tabular}{|c|c|c|c|}
\hline \multirow{2}{*}{ Variables } & \multicolumn{2}{|c|}{ All } & Subgroup \\
\cline { 2 - 4 } & Model 1 & Model 2 & Model 3 \\
\hline Age & $-0.043^{*}$ & $-0.050^{*}$ & -0.018 \\
& $(0.025)$ & $(0.028)$ & $(0.030)$ \\
\hline Years of education & -0.068 & -0.057 & -0.065 \\
& $(0.053)$ & $(0.054)$ & $(0.062)$ \\
\hline 0-year-old child & $1.356^{* * *}$ & $1.166^{* * *}$ & $1.185^{* *}$ \\
& $(0.408)$ & $(0.433)$ & $(0.460)$ \\
\hline 1-year-old child & 0.722 & 0.612 & 0.538 \\
& $(0.545)$ & $(0.532)$ & $(0.555)$ \\
\hline 2-year-old child & $0.739^{*}$ & $0.797^{*}$ & 0.705 \\
& $(0.449)$ & $(0.445)$ & $(0.460)$ \\
\hline 3-year-old child & $1.024^{* * *}$ & $1.079^{* * *}$ & $0.964^{* * *}$ \\
& $(0.356)$ & $(0.362)$ & $(0.369)$ \\
\hline 4-year-old child & 0.627 & 0.599 & 0.493 \\
& $(0.421)$ & $(0.428)$ & $(0.449)$ \\
\hline 5-year-old child & $1.030^{\star * *}$ & $0.939^{* * *}$ & $0.829^{* *}$ \\
& $(0.355)$ & $(0.361)$ & $(0.381)$ \\
\hline 6-year-old child & 0.625 & 0.524 & 0.330 \\
& $(0.387)$ & $(0.395)$ & $(0.412)$ \\
\hline 7-year-old child & $0.991^{* * *}$ & $0.947^{* * *}$ & $0.803^{* *}$ \\
& $(0.304)$ & $(0.309)$ & $(0.337)$ \\
\hline 8-year-old child & $0.571^{* *}$ & $0.525^{*}$ & 0.390 \\
& $(0.277)$ & $(0.283)$ & $(0.292)$ \\
\hline 9-year-old child & -0.238 & -0.287 & -0.409 \\
& $(0.374)$ & $(0.375)$ & $(0.391)$ \\
\hline The number of & -0.501 & -0.526 & -0.451 \\
children under age 7 & $(0.427)$ & $(0.426)$ & $(0.434)$ \\
\hline Household debt & 0.115 & 0.142 & 0.123 \\
& $(0.090)$ & $(0.089)$ & $(0.097)$ \\
\hline Husband's hourly & 0.015 & 0.012 & -0.034 \\
wage & $(0.097)$ & $(0.094)$ & $(0.102)$ \\
\hline Husband's weekly & -0.016 & -0.018 & -0.013 \\
working hours & $(0.023)$ & $(0.025)$ & $(0.026)$ \\
\hline Observations & 1,412 & 1,412 & 960 \\
\hline
\end{tabular}

Note: a) Models include constants. Robust standard errors in parenthesis.

*** $p<0.01{ }^{* *} p<0.05,{ }^{*} p<0.10$

b) Year dummies are included in Model 2 and Model 3.

c) The subgroup is a group of women from the sample who have given a birth to a child during survey years (1998-2016)

\section{Discussion}

\section{1. 연구결과 및 시사점}

본 논문은 자녀의 나이가 기혼여성의 경력 재단절에 미치는 영향을 생존분석모형으로 살펴보았다. 표본을 퇴직 당시 만 12세 이하 자녀가 있는 경우로 설정하고, 만 0 9세 자녀연령 더미를 주요 설명변수로 사용했다. 이외에도 만 7세 이하 자 녀 수 더미, 여성 본인의 나이, 직업 시작 당시 특성, 남편의 임금률과 근로시간, 가구 부채를 설명변수에 포함했다. 분석결 과 모든 모형에서 만 0 세 자녀의 영향이 가장 크고 유의하게 나타났다. 여성의 경제활동 참여에서 전통적으로 언급되는 남 편의 임금은 유의하지 않았다.

경제활동인구로 유입된 후 $30 \%$ 정도의 여성이 다시 비경제 활동인구로 전환했는데, 두 번째 경력단절에서 출산 후(자녀 
만 0세 시기)에 경력단절 확률이 가장 높았다. 이후 자녀가 성 장하면서 어머니의 노동공급에 미치는 영향은 감소했지만, 만 3 세와 7 세 시기에 위험비율이 크게 증가하여 여성들은 경력지 속에 위기를 겪는 것으로 나타났다.

그동안 여성의 노동공급 결정에 대한 연구는 미취학 자녀와 배우자 효과에 집중해왔다. 본 논문에서는 취학 이후 시기도 분석에 포함하여, 경력 재단절 시기에 만 7 세 자녀가 영유아 자녀와 동일한 수준의 영향을 미치는 것을 확인했다. 초등학교 입학 시기의 효과에 대한 실증연구는 부족하지만, 맞벌이 여성 들이 자녀의 초등학교 입학 시기에 육아휴직 사용을 희망하거 나 여의치 않을 경우 퇴직을 고려한다는 사실은 어린 자녀를 둔 주변의 기혼 여성들이나 신문기사, 온라인 커뮤니티 등에서 충분히 확인할 수 있다. 저학년 자녀들을 위한 방과 후 돌봄 교실을 운영 중이지만, 수요보다 공급이 부족하다. 정부는 시 간제 일자리 공급 확대, 근로시간 단축 등 노동시장의 측면에 서 해결방안을 마련하고 있다. 그러나 자녀의 등하교시간이 여 성의 출퇴근 시간과 맞지 않기 때문에 방과 후 학원 순례를 시킬 수밖에 없는 현실을 고려하면, 교육제도 측면에서도 해결 방안을 찾아볼 필요가 있다.

본 논문의 분석 결과는 기업 경영의 측면에서도 참고할 만 한 정보를 제공한다. 여성의 경력단절은 기업에게는 숙련노동 의 상실을 의미하므로, 이를 적절히 방지할 경우 고숙련 인력 수급 및 생산성 증대에 도움이 될 수 있다. 그동안 기업 차원 에서도 출산, 육아에 대해 다채롭게 지원이 이루어졌다. 본고 의 분석 결과는 이러한 지원제도를 설계할 때 자녀의 연령 변 화를 보다 세심하게 고려하면 더욱 효과적일 수 있음을 시사 한다. 특히, 기업의 생산성 증대는 산업경쟁력 강화로 이어질 수 있으므로, 각 기업이 여성의 경력재단절을 줄이기 위한 제 도를 도입할 수 있도록 정부가 적절히 지원하고 기업의 행동 변화를 가져올 수 있는 유인체계를 제공할 필요도 있다.

\section{2. 한계점 및 후속 연구 방향}

본 연구의 한계는 자녀 효과를 연령 더미만으로 분석하는 데 그쳤다는 점이다. 자녀 나이 더미는 역인과관계로 인한 내 생성 문제는 피할 수 있으나, 누락변수 편의 문제에서 자유로 울 수 없다. 사용 변수의 다양성도 부족하다. 노동패널에는 보 육비용에 대한 항목이 존재하지만, 차수마다 조사항목이 일관 되지 않고, 일부 자녀에 대해서만 조사하기 때문에 분석에서 자녀 양육비용 변수를 포함하지 않았다. 또한, 보육비용과 경 제활동 참여 사이에 내생성이 존재할 수 있다. 예를 들어, 퇴 근 시간에 맞추기 위해 아이들을 학원에 보내거나, 하원 및 하 교 도우미를 고용하는 경우 보육교육비지출과 경제활동 참여 간에 역인과관계가 발생한다.

앞으로 후속 연구에서는 누락변수 편의 문제를 극복하기 위 한 연구방법론을 모색할 필요가 있다. 새로운 통제변수를 개발 하여 분석에 추가하는 방법도 권장된다. 보육비용과 경제활동 참여 사이의 내생성 문제는 도구변수 분석이나 준실험적 방법 을 적용하여 해결을 시도해 볼 수 있다.

마지막으로, 본 연구는 요즈음 우리 사회에서 폭넓게 논의 가 이루어지고 있는 일(work)과 삶(life)의 균형에 대해 직접적 으로 언급하고 있지 않다. 경제학 선행 연구문헌과 마찬가지로 소비 증진을 위한 개인의 노동공급과 여타의 삶, 즉 여가 사이 의 균형에 대한 결정은 선호체계의 특정에 따라 이루어진다고 가정하고 이론 모형과 이후 실증 분석을 진행하였지만, 일과
소비 사이의 대체탄력성에 구체적으로 분석을 수행하지는 않 았다. 더욱 세분화된 이론 모형을 기반으로 일과 소비 사이의 대체탄력성을 추정하고, 이를 이용하여 여성의 경력 재단절에 대해 분석해보는 접근방식도 후속 연구에서 고려해 볼 만하다.

\section{References}

Angrist, J. D., \& Evans, W. N. (1998). Children and their parents' labor supply: Evidence from exogenous variation in family size. American Economic Review, 88(3), 450-477.

Bailey, M. J. (2006). More power to the pill: The impact of contraceptive freedom on women's life cycle labor supply. Quarterly Journal of Economics, 121(1), 289-320.

Baker, M., Gruber, J., \& Milligan, K. (2008). Universal child care, maternal labor supply, and family well-being. Journal of Political Economy, 116(4), 709-745.

Becker, G. S. (1985). Human capital, effort, and the sexual division of labor. Journal of Labor Economics, 3(1, Part 2), S33-S58.

Cleves, M. (2008). An Introduction to Survival Analysis Using Stata. College Station, TX: Stata Press.

Gelbach, J. B. (2002). Public schooling for young children and maternal labor supply. American Economic Review, 92(1), 307-322.

Go, S., \& Kim, J. (2017). Impact of railroads on local economies: Evidence from U.S. History. Journal of Distribution Science, 15(4), 25-32.

Goldin, C. (1992). Understanding the Gender Gap: An Economic History of American Women. New York, NY: Oxford University Press.

Goldin, C., \& Katz, L. F. (2002). The power of the pill: Oral contraceptives and women's career and marriage decisions. Journal of Political Economy, 110(4), 730-770.

Goldin, C., \& Mitchell, J. (2017). The new life cycle of women's employment: Disappearing humps, sagging middles, expanding tops. Journal of Economic Perspectives, 31(1), 161-82.

Gwon, J. (2015). A strategic effect of bundling on product distribution. Journal of Distribution Science, 13(10), 15-21.

Haeck, C., Lefebvre, P., \& Merrigan, P. (2015). Canadian evidence on ten years of universal preschool policies: The good and the bad. Labour Economics, 36, 137-157.

Havnes, T., \& Mogstad, M. (2011). Money for nothing? Universal child care and maternal employment. 
Journal of Public Economics, 95(11-12), 14551465.

Heckman, J. J. (1974). Effects of child-care programs on women's work effort. Journal of Political Economy, 82(2, Part 2), S136-S163.

Jeon, S. H. (2008). The impact of lifecycle events on women's labour force transitions: A panel analysis. Economic Record, 84(Special Issue), 83-98.

Kiefer, N. M. (1988). Economic duration data and hazard functions. Journal of Economic Literature, 26(2), 646-679.

Klerman, J. A., \& Leibowitz, A. (1990). Child care and women's return to work after childbirth. American Economic Review, 80(2), 284-288.

Lundborg, P., Plug, E., \& Rasmussen, A. W. (2017). Can women have children and a career? IV evidence from IVF treatments. American Economic Review, 107(6), 1611-1637.

Lundin, D., Mörk, E., \& Öckert, B. (2008). How far can reduced childcare prices push female labour supply?. Labour Economics, 15(4), 647-659.
Mincer, J. (1962). Labor Force Participation of Married Women: A Study of Labor Supply. in H. Gregg Lewis (ed.), Aspects of Labor Economics. Universities-National Bureau Committee for Economic Research. Princeton, NJ: Princeton University Press.

Paull, G. (2008). Children and women's hours of work. Economic Journal, 118(526), F8-F27.

Statistics Korea (2017a). Economically Active Population Survey. Retrieved May 1, 2018 from http://kosis.kr/ eng/statisticsList/statisticsList_01List.jsp?vwcd=MT_E TITLE\& parmTabld=M_01_01

Statistics Korea (2017b). Local Area Labor Force Survey. Retrieved May 1, 2018 from http://kosis.kr/ statisticsList/statisticsListIndex.do?menuld=M_01_01 \&vwcd=MT_ZTITLE\&parmTabld=M_01_01\#SelectSta tsBoxDiv

Yao, X., \& Kwak, J. (2017). Study on mobile terminal distribution act: Effects of subsidy regulations. Journal of Distribution Science, 15(12), 53-60. 